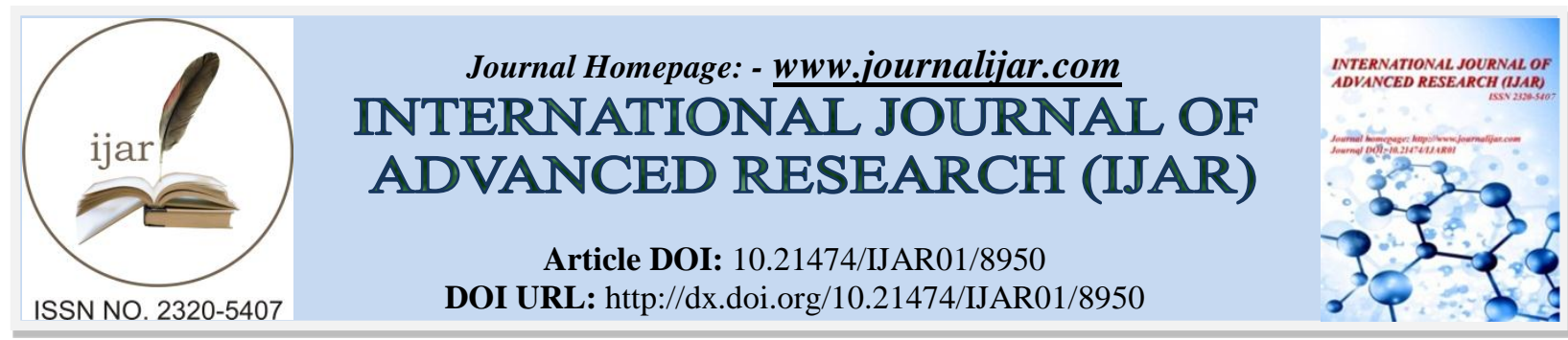

RESEARCH ARTICLE

\title{
“CORRELATION OF CORRECTED QT INTERVAL WITH QUANTITATIVE CARDIAC TROPONIN-I LEVELS AND ITS PROGNOSTIC ROLE IN NON ST ELEVATION MYOCARDIAL INFARCTION.
}

Routray S. N. ${ }^{1}$, Satapathy M. K. ${ }^{2}$, Mohanty N. $K^{3}$, Satpathy C. ${ }^{3}$ and Dash B. $K^{4}$.

1. Professor, Dept.of Cardiology, S.C.B Medical College, Cuttack, Odisha, India.

2. Senior Resident, Dept.of Cardiology, S.C.B Medical College, Cuttack, Odisha, India.

3. Asso. Professor, Dept.of Cardiology, S.C.B Medical College, Cuttack, Odisha, India.

4. Asst. Professor, Dept.of Cardiology, S.C.B Medical College, Cuttack, Odisha, India.

\section{Manuscript Info}

..........................

Manuscript History

Received: 22 February 2019

Final Accepted: 24 March 2019

Published: April 2019

\section{Abstract}

Background: There is a large body of evidence of specific myocardial injury markers such as cardiac troponin $\mathrm{I}(\mathrm{cTnI})$ and cardiac troponin $\mathrm{T}$ (çTnT) for short and long-term prognostic values of NSTE-ACS mortality and new infarction. Objective: The present study was conducted to assess the correlation between corrected QT interval with cardiac troponin-I levels in NSTE-MI patients and to assess if prolonged corrected QT interval independently predicts higher 30-day Major Adverse Cardiac Events (MACE) in NSTE-MI patients. Material and Method: we enrolled 301 patients with the diagnosis of NSTEMI. Demographic variables at admission were age, gender, arterial pressure, history of CAD, hypertension, diabetes mellitus, smoking, dyslipidemia, previous coronary revascularization, and medication before entering the study. All patients were classified at admission according to the TIMI score for NSTE-ACS.Cardiac troponin I was measured in all cases with the sample collected $24 \mathrm{hr}$ after the beginning of last angina episode. Concentrations $\geq 0.01 \mathrm{ng} / \mathrm{ml}$ were considered to be positive. A second measurement was done after $12 \mathrm{~h}$ in patients in whom the first determination is negative.Corrected QT interval(longest) measurement was done according to American Heart association guidelines. Patients were treated as per protocol. Major adverse cardiovascular events (includes, death due to cardiovascular cause, Non-fatal Myocardial Infarction and Recurrent Unstable Angina and ensuing urgent revascularization.) that were observed up to 30 days post discharge. Results: Troponin-I values and QTc interval was significantly higher in patients with diabetes and dyslipidemia, who presented with higher TIMI scores, severe LV systolic dysfunction ,higher killip class and hypotension and with multivessel disease, did not differ significantly according to culprit vessel. There was significant correlation with coefficient of 0.637 between QTc-max and Troponin I.Patients with MACE had significantly higher mean Troponin - I and mean QTc interval. Conclusion: Corrected QT interval has a strongly positive significant correlation with quantitative troponin I level in NSTEMI patients and Prolonged corrected QT interval is independently predictive of higher

Corresponding Author:-Routray S. N.

Address:-Professor, Dept.of Cardiology, S.C.B Medical College, Cuttack, Odisha, India. 
rate of major adverse cardiovascular events after NSTEMI within 30 days post discharge.

Copy Right, IJAR, 2019,. All rights reserved.

\section{Introduction:-}

The latest American College of Cardiology and the American Heart Association (ACC/AHA) and European Society of Cardiology (ESC) guidelines recognize the importance of early risk stratification in the management of NSTEACS and recommend an integrated approach to risk assessment. The information required for this assessment is derived from the patient's history and physical examination, electrocardiogram (ECG) and cardiac biomarkers.

It has been shown that the corrected QT interval prolongation is an independent risk marker in NSTE-ACS .However, there is scarce information about its relationship with other variables of known prognostic value, such as cardiac troponins.

There is a large body of evidence of specific myocardial injury markers such as cardiac troponin I (cTnI) and cardiac troponin $\mathrm{T}$ (çTnT) for short and long-term prognostic values of NSTE-ACS mortality and new infarction. ${ }^{3-6}$

Several studies have been published showing the prolonged corrected QT interval (QTc) in 12 lead ECG as an independent risk marker in NSTE-ACS with or without acute ischemic changes, both at 30-day post-discharge or long-term followup. ${ }^{7-9}$

\section{Aims and objectives:-}

1)To assess the correlation between corrected QT interval and cardiac troponin-I levels in NSTE-MI patients. 2) To assess if prolonged corrected QT interval independently predicts higher 30-day Major Adverse Cardiac Events (MACE) in NSTE-MI patients.

\section{Methods:-}

Patients with NSTEMI ( defined as abnormal cardiac Troponin $\mathrm{I} \geq 0.01 \mathrm{ng} / \mathrm{ml}$ )was included in the study . A standard ECG recorded, at admission then at $6 \mathrm{hr}, 12 \mathrm{hr}, 24 \mathrm{hr}$ and $48 \mathrm{hr}$ post-admission. Blood samples were obtained at admission for complete blood count, serum urea, creatinine, electrolytes, A Fasting lipid profile was also done within $24 \mathrm{hrs}$ of admission. Upon admission to the hospital all patients received conventional treatment according to existing departmental protocol.

Demographic variables at admission registered were age, gender, arterial pressure, history of CAD, hypertension, diabetes mellitus, smoking, dyslipidemia, previous coronary revascularization, and medication before entering the study. After basal characterization and TIMI scoring ${ }^{10}$, all patients were followed-up for 30 days after discharge.

QT interval measurement was done according to American Heart association guidelines. , maximum interval taken in the ECG within $48 \mathrm{~h}$ post admission. AHA linear regression formula was used to calculate QTc according to HR. ${ }^{11,12}$ Corrected QT(QTc) $=$ Observed QT +1.75( observed HR-60)

Cardiac troponin I was measured with the sample collected $24 \mathrm{hr}$ after the beginning of last angina episode. A second measurement was done after $12 \mathrm{~h}$ in patients in whom the first determination is negative

Major adverse cardiovascular events (MACE) that were observed up to 30 days post discharge were death due to cardiovascular cause, Non-fatal Myocardial Infarction (defined by increased cardiac biomarkers, characteristic dynamic and evolving electrocardiographic changes. and prolonged chest discomfort), and Recurrent Unstable Angina and ensuing urgent revascularization. Patients were divided into two groups according to the presence (group A) or absence (group B) of MACE.

\section{Inclusion criteria:}

Male and female patients, more than 18 years of age, admitted with diagnosis of Non-ST elevation myocardial infarction, with or without acute ischemic ECG changes.

\section{Exclusion criteria:}

1.ST-segment-elevation-AMI,Unstable Angina-ACS. 2.Flat T wave $(<1 \mathrm{~mm})$, Wide QRS, Ventricular hypertrophy 3.Serum potassium $\leq 3.5 . \mathrm{meq} / \mathrm{I}$ or $>5.5 \mathrm{meq} / \mathrm{L}$,Serum calcium $<8.5 \mathrm{mg} / \mathrm{dl}$ or $>10.5 \mathrm{mg}$ 4.Severe valvular disease or 
cardiomyopathy 5.Patients receiving antiarrhythmic or QT interval modifying drugs 6. Wolff-Parkinson-White abnormality, atrial fibrillation, atrial flutter or frequent extrasystoles (>10/min)

\section{Statistical analysis:}

Continuous variables with normal distribution were expressed as mean \pm standard deviation (SD) and continuous variables with non-normal distribution were expressed as median (interquartile range). Unpaired Student's t test was used to compare continuous variables, and Chi square test was used to compare continuous variables, as appropriate. Spearman's correlation test was employed to establish the correlation between troponin-I level and QTc max values. Multivariate logistic regression analysis was performed to identify independent predictors of MACE.

\section{Ethic Statement:}

Study procedure was approved by Institutional Ethics Committee of S.C.B. Medical college and Hospital,Cuttack,Odisha(Regd.No ECR/84/Inst/OR/2013)while grant for the study was approved by the institutional Review Board vide Ref.No.766/15.1.2019. Written consent was sorted prior to participation from respondents by means of informed consent.

\section{Results:-}

Mean age of the patients was $54.2 \pm 12.3$ years. $212(70.4 \%)$ were males and $89(29.6 \%)$ were females. Mean age of male and femals patients was $52.2 \pm 12.4$ years and 58.8 \pm 10.7 years, respectively.Maximum no of patients 172 $(57.1 \%)$ patients were in $46-70$ years age group.

\begin{tabular}{|l|l|l|}
\hline AGE GROUP & NO. OF PATIENTS & PERCENTAGE \\
\hline$<45$ YEARS & 90 & 29.9 \\
\hline $46-70$ YEARS & 172 & 57.1 \\
\hline$>70$ YEARS & 39 & 13.0 \\
\hline TOTAL & 301 & 100.0 \\
\hline
\end{tabular}

Maximum no patients 158 (52.5\%) were either active smokers or had stopped smoking in past six months, 113(37 $.5 \%)$ patients were diabetics and $102(34 \%)$ had a history of hypertension. 63(20.9\%) patients had history of CAD and dyslipidemia was present in $108(36 \%)$ patients

\begin{tabular}{|l|l|l|}
\hline RISK FACTOR & TOTAL & PERCENTAGE \\
\hline DIABETES & 113 & 37.5 \\
\hline HYPERTENSION & 102 & 34 \\
\hline CAD & 63 & 20.9 \\
\hline SMOKERS & 158 & 52.5 \\
\hline DYSLIPIDEMIA & 108 & 36 \\
\hline
\end{tabular}

Mean value of maximum troponin I levels in total sample population was $3.53 \pm 2.88 \mathrm{ng} / \mathrm{ml}$. Mean value was not significantly different between male $(3.73 \pm 2.96 \mathrm{ng} / \mathrm{ml}$, $)$ and female $\operatorname{sex}(3.06 \pm 2.65 \mathrm{ng} / \mathrm{ml}$,$) . (\mathrm{p}=0.06)$ and was not significantly different according to age groups. ( $p>0.1)$.

Mean Troponin I value was significantly higher in patients with diabetes $4.12 \pm 3.14 \mathrm{ng} / \mathrm{ml}$, vs patients without diabetes $3.17 \pm 2.66 \mathrm{ng} / \mathrm{ml}(\mathrm{P}=0.006)$ and in patients with dyslipidemia $3.84 \pm 3.05 \mathrm{ng} / \mathrm{ml}$, vs patients without dyslipidemia, $3.09 \pm 2.58 \mathrm{ng} / \mathrm{ml}(\mathrm{p}=0.02)$.

Mean Troponin I value varied significantly according to TIMI score,SBP, Killip classes,LVEF. Mean value was lowest $(2.9 \pm 2.6 \mathrm{ng} / \mathrm{ml}$ )in TIMI $0-2$ group $(\mathrm{p}=0.01)$, and highest $(5.9 \pm 2.7 \mathrm{ng} / \mathrm{ml})$ in TIMI $5-7$ group (p <0.01). Mean value was highest at $6.07 \pm 2.56 \mathrm{ng} / \mathrm{ml}$ in SBP $<90 \mathrm{~mm} \mathrm{Hg}$ group lowest at $3.10 \pm 2.69 \mathrm{ng} / \mathrm{ml}$ in SBP 90-140 $\mathrm{mmHg}$ group $(\mathrm{p}<0.01)$. Mean value was $3.01 \pm 2.59 \mathrm{ng} / \mathrm{ml}$ in Killip class I group $(\mathrm{p}<0.01)$ and $6.11 \pm 2.88 \mathrm{ng} / \mathrm{ml}$ in Killip class higher than I group $(\mathrm{p}<0.001)$. Mean value was highest at $6.37 \pm 2.41 \mathrm{ng} / \mathrm{ml}$ in LVEF $<35 \%$ group ( $\mathrm{p}<0.01$ ), and lowest at $1.49 \pm 0.75 \mathrm{ng} / \mathrm{ml}$ in $\mathrm{LVEF}>50 \%$ group $(\mathrm{p}<0.01)$, respectively.

Patient Profile \& Trop-I Level
\begin{tabular}{|l|l|l|}
\hline \multicolumn{2}{|c|}{ PATIENT PROFILE } & MEAN TROP I LEVEL (ng/ml) \\
\hline & $18-45 \mathrm{yrs}$ & $3.38 \pm 3.03$ \\
\cline { 2 - 3 } & $46-70 \mathrm{yrs}$ & $3.49 \pm 2.78$ \\
\hline
\end{tabular}




\begin{tabular}{|c|c|c|}
\hline AGE (in years) & >70yrs & $4.06 \pm 2.98$ \\
\hline \multirow[b]{2}{*}{ DIABETES } & PRESENT & $4.12 \pm 3.14$ \\
\hline & ABSENT & $3.17 \pm 2.66$ \\
\hline \multirow[b]{2}{*}{ HYPERTENSION } & PRESENT & $3.56 \pm 2.95$ \\
\hline & ABSENT & $3.5 \pm 2.81$ \\
\hline \multirow[b]{2}{*}{ DYSLIPIDEMIA } & PRESENT & $3.84 \pm 3.05$ \\
\hline & ABSENT & $3.09 \pm 2.58$ \\
\hline \multirow[b]{2}{*}{ SMOKING } & PRESENT & $3.72 \pm 3.08$ \\
\hline & ABSENT & $3.15 \pm 2.42$ \\
\hline \multirow[b]{2}{*}{ CAD } & PRESENT & $3.33 \pm 2.84$ \\
\hline & ABSENT & $3.58 \pm 2.90$ \\
\hline \multirow[b]{3}{*}{ TIMI SCORE } & $0-2$ & $2.90 \pm 2.60$ \\
\hline & $3-4$ & $3.70 \pm 2.90$ \\
\hline & $5-7$ & $5.90 \pm 2.70$ \\
\hline \multirow{3}{*}{$\begin{array}{l}\text { SYSTOLIC BLOOD PRESSURE } \\
(\mathrm{mmHg})\end{array}$} & $<90$ & $6.07 \pm 2.56$ \\
\hline & $90-140$ & $3.10 \pm 2.69$ \\
\hline & $>140$ & $3.85 \pm 3.04$ \\
\hline \multirow[b]{2}{*}{ KILLIP CLASS } & 1 & $3.01 \pm 2.59$ \\
\hline & $>1$ & $6.11 \pm 2.88$ \\
\hline \multirow{3}{*}{$\operatorname{LVEF}(\%)$} & $<35$ & $6.37 \pm 2.41$ \\
\hline & $35-50$ & $2.49 \pm 2.28$ \\
\hline & $>50$ & $1.49 \pm 0.75$ \\
\hline
\end{tabular}

Mean value of maximum QTc interval in total population was $472.31 \pm 28.65 \mathrm{~ms}$. and did not differ significantly between male patients $(471.9 \pm 28.6 \mathrm{~ms})$, and female patients $(473.3 \pm 28.7 \mathrm{~ms}) \mathrm{p}=0.7$. Mean valueQTc, in age group of less than 70 years was $470.81 \pm 28.78$ ms which was significantly lower than mean value in more than 70 year age group, $482.41 \pm 25.94 \mathrm{~ms},(\mathrm{p}=0.018)$.

Mean corrected QT interval was significantly higher in patients with diabetes $478.74 \pm 30.29 \mathrm{~ms}$, compared to patients without diabetes $468.45 \pm 26.97 \mathrm{~ms}(\mathrm{p}=0.002)$ and with dyslipidemia $475.24 \pm 29.96 \mathrm{~ms}$, compared to patients without dyslipidemia $466.52 \pm 26.07 \mathrm{~ms}(\mathrm{p}=0.014)$, did not differ significantly among patients with or without hypertension, history of smoking, and history of CAD.

Mean value was lowest at $463.58 \pm 26.16 \mathrm{~ms}$, in TIMI $0-2$ group ( $<0.001$ ), and highest at $504.31 \pm 21.78 \mathrm{~ms}$, in TIMI 5 -7 group ( $<<0.001$ ), respectively. Mean value was lower at $470.65 \pm 28.05 \mathrm{~ms}$, in SBP $\geq 90 \mathrm{mmHg}$ group, and higher at $498.41 \pm 25.88$ runs in SBP $<90 \mathrm{mmHg}$ group $(\mathrm{p}<0.001)$, respectively. Mean value was lower at $468.22 \pm 27.43 \mathrm{~ms}$, in Killip class 1, and higher at $492.38 \pm 26.19 \mathrm{~ms}$ in Killip class > 1 group ( $<<0.001)$. . Mean value was lower at $469.09 \pm 28.15 \mathrm{~ms}$, in LVEF $\geq 35 \%$ group, and higher at $490.15 \pm 24.81 \mathrm{~ms}$ in LVEF < 35\% group ( $<0.001$ ), respectively.

Patient Profile And Corrected Qt Interval

\begin{tabular}{|l|l|l|}
\hline \multicolumn{2}{|l|}{ PATIENT PROFILE } & MEAN QTc MAX (ms) \\
\hline \multirow{2}{*}{ AGE(in years) } & $<70$ & $470.81 \pm 28.78$ \\
\cline { 2 - 3 } & $>70$ & $482.42 \pm 25.94$ \\
\hline \multirow{2}{*}{ DIABETES } & PRESENT & $478.74 \pm 30.29$ \\
\cline { 2 - 3 } & ABSENT & $468.45 \pm 26.97$ \\
\hline \multirow{2}{*}{ HYPERTENSION } & PRESENT & $473.33 \pm 28.77$ \\
\cline { 2 - 3 } & ABSENT & $471.11 \pm 28.57$ \\
\hline \multirow{2}{*}{ DYSLIPIDEMIA } & PRESENT & $475.24 \pm 29.96$ \\
\cline { 2 - 3 } & ABSENT & $466.52 \pm 26.07$ \\
\hline \multirow{2}{*}{ SMOKING } & PRESENT & $472.89 \pm 28.76$ \\
\cline { 2 - 3 } & ABSENT & $471.17 \pm 28.55$ \\
\hline \multirow{2}{*}{ CAD } & PRESENT & $472.53 \pm 29.27$ \\
\cline { 2 - 3 } & ABSENT & $472.25 \pm 28.55$ \\
\hline
\end{tabular}




\begin{tabular}{|l|l|l|}
\hline \multirow{2}{*}{ TIMI SCORE } & $0-2$ & $463.58 \pm 26.16$ \\
\cline { 2 - 3 } & $3-4$ & $475.17 \pm 28.03$ \\
\cline { 2 - 3 } & $5-7$ & $504.31 \pm 21.78$ \\
\hline \multirow{2}{*}{$\begin{array}{l}\text { SYSTOLIC BLOOD PRESSURE } \\
(\mathrm{mmHg})\end{array}$} & $<90$ & $498.41 \pm 25.88$ \\
\cline { 2 - 3 } & $\geq 90$ & $470.65 \pm 28.05$ \\
\hline \multirow{2}{*}{ KILLIP CLASS } & $\mathrm{I}$ & $468.22 \pm 27.43$ \\
\cline { 2 - 3 } & $>\mathrm{I}$ & $492.38 \pm 26.19$ \\
\hline \multirow{2}{*}{ LVEF (\%) } & $<35$ & $490.15 \pm 24.81$ \\
\cline { 2 - 3 } & $\geq 35$ & $469.09 \pm 28.15$ \\
\hline
\end{tabular}

Maximum patients have single vessel disease i.e 181(60.1\%) out of which 114 (62.9\%) patients had Left anterior descending artery (LAD), 24 (13.2\%) patients had Left circumflex artery (LCX) and Forty three (23.7\%) patients had Right coronary artery (RCA) as culprit vessel. Multivessel disease with significant lesion in vessel other than culprit artery was found in $101(33.5 \%)$ patients. Out of which 51(50.5\%) patients had LAD ,Seventeen (16.8\%) patients had LCX and 26(25.7\%) patients had RCA as the culprit vessel. Nineteen (6.3\%) patients had either non significant CAD or normal angiogram and 14 patients (13.9\%) had significant Left Main disease . Culprit vessel could not be identified in 7 patients $(6.9 \%)$ as more than 1 vessel was critically diseased

\begin{tabular}{|l|l|l|}
\hline VESSEL INVOLVED IN CAG & NO. OF PATIENTS & PERCENTAGE \\
\hline SINGLE VESSEL DISEASE & 181 & 60.1 \\
\hline MULTI VESSEL DISEASE & 101 & 33.5 \\
\hline NORMAL CORONARIES & 19 & 6.3 \\
\hline
\end{tabular}

Mean Troponin-I value was significantly higher in patients with multivessel disease $4.14 \pm 3.20 \mathrm{ng} / \mathrm{ml}$ vs single vessel disease on angiogram $3.17 \pm 2.62 \mathrm{ng} / \mathrm{ml}(\mathrm{p}<0.005)$

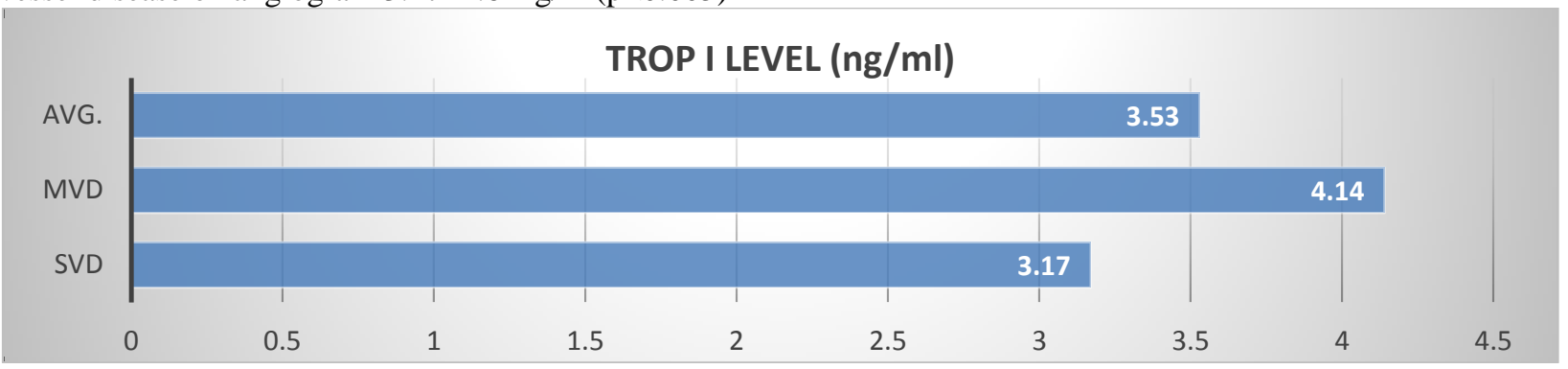

Mean corrected QT interval was significantly higher in patients with multivessel disease (478.16 $\pm 30.50 \mathrm{~ms})$, vs single vessel disease on angiogram $468.89 \pm 26.02 \mathrm{~ms}(\mathrm{p}=0.009)$.

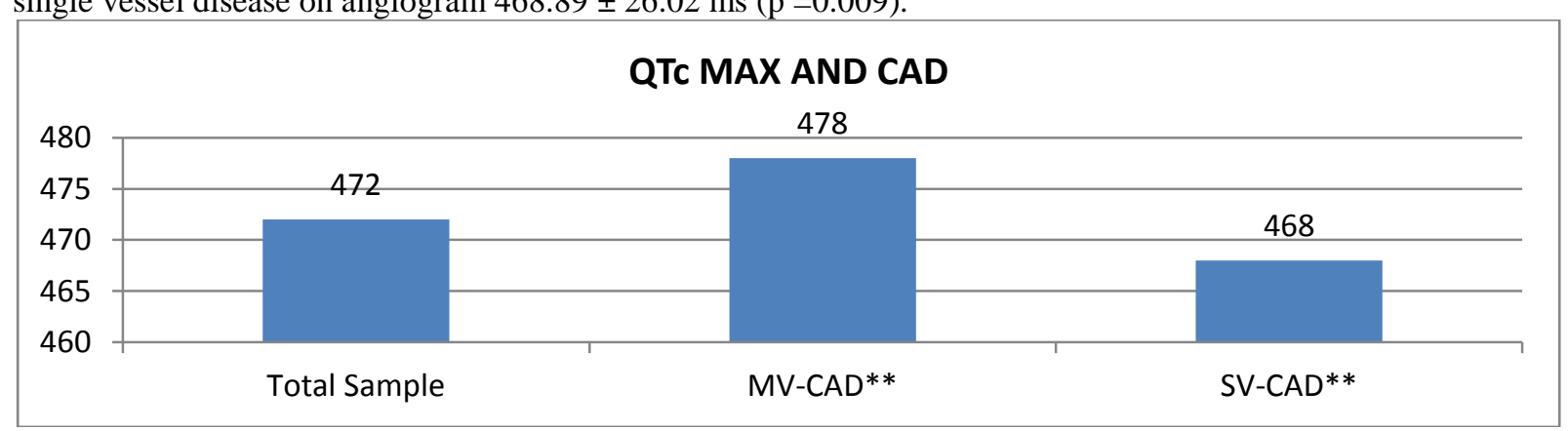

The Spearman correlation coefficient of 0.637 between QTc-max and Troponin- I, (p <0.001).

\section{Mace}

MACE has occurred in 77 out of 301 patients (25.6\%) within 30 days follow-up after hospital discharge. These patients were classified into Group A. Out of these patients, 14/301 (4.6\%) patients expired, including 3 cases of sudden cardiac death, 22/301 (7.3\%) patients had suffered recurrent MI. Forty one out of 301 (13.6\%) patients suffered Unstable Angina requiring revascularization within 30 days. The 224 out of 301 (74.4\%) patients who did not suffer MACE within 30 days post discharge, were classified into Group B.

\begin{tabular}{|l|l|l|}
\hline MACE EVENTS & NO. OF PATIENTS & PERCENTAGE \\
\hline
\end{tabular}




\begin{tabular}{|l|l|l|}
\hline DEATH & 14 & 18.18 \\
\hline MYOCARDIAL INFARCTION & 22 & 28.57 \\
\hline URGENT REVASCULARISATION & 41 & 53.24 \\
\hline
\end{tabular}

Group A patients were significantly older $(60.19 \pm 11.64$ years $)$ compared to group $\mathrm{B}(52.13 \pm 11.9$ years $)$ (p $<0.001)$. Proportion of males was significantly more in Group B, $167(74.6 \%)$ vs $45(58.4 \%)$ in group A (p 0.007). Diabetes was significantly more frequent in Group A, $40(51.9 \%)$ patients vs $73(32.6 \%)$ in group $\mathrm{B}(\mathrm{p}=$ 0.004). Dyslipidemia, Hypertension, Smoking, and history of CAD did not differ significantly among group A and B patients. Group A patients had significantly higher mean Troponin I level $4.62 \pm 3.01 \mathrm{ng} / \mathrm{ml}$, compared to group B patients, $3.16 \pm 2.74 \mathrm{ng} / \mathrm{ml}$ ( $\mathrm{p}<0.001$ ). and significantly higher mean corrected QT interval $482.16 \pm 27.23 \mathrm{~ms}$, compared to group B patients, $468.93 \pm 28.41 \mathrm{~ms}(\mathrm{p}<0.001)$.
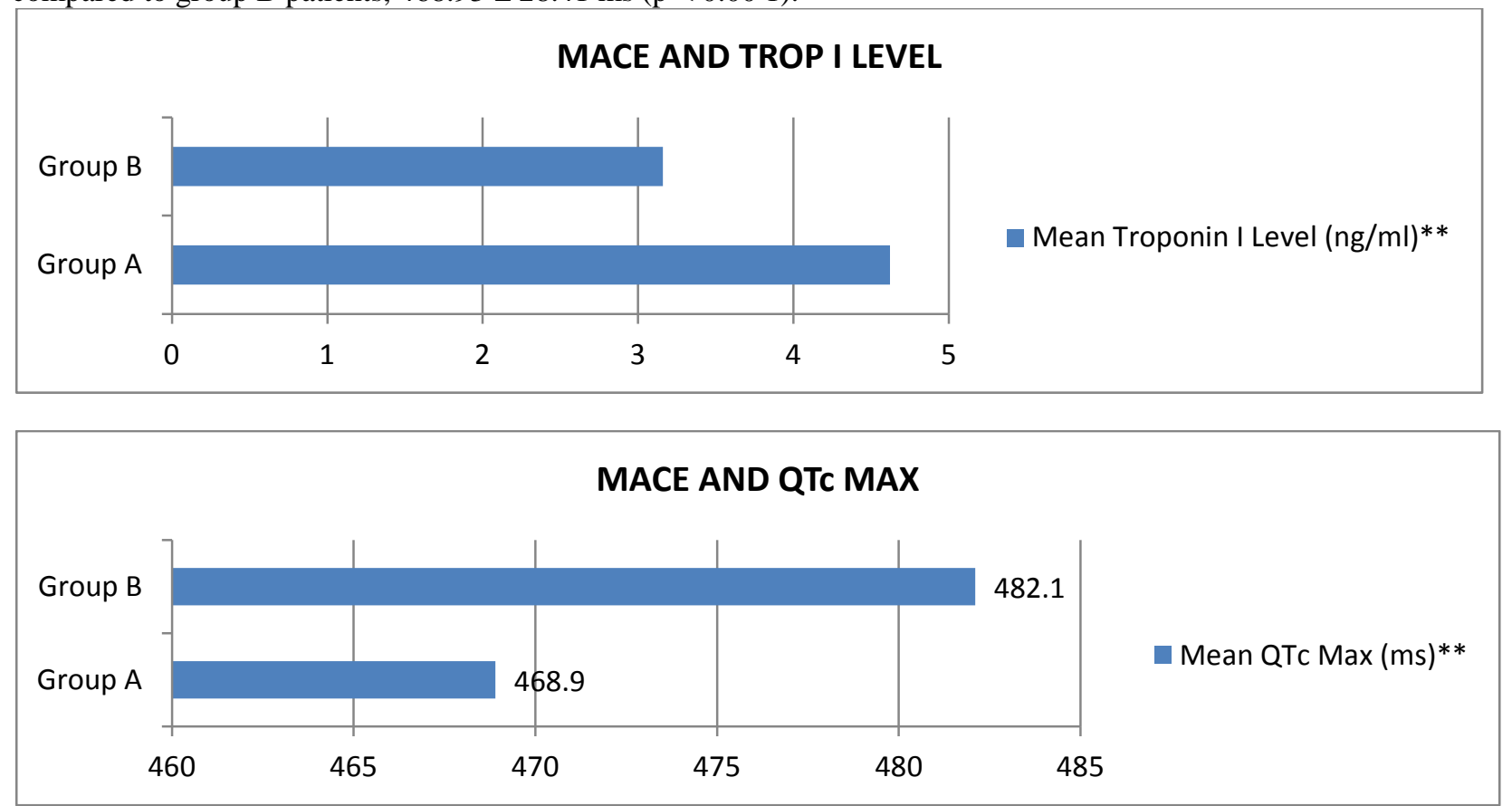

In multivariate analysis of a logistic regression model with variables with $\mathrm{p}<0.05$, TIMI score $>2$ (OR 9.9, $\mathrm{p}$ $<0.001,95 \%$ CI 3.90-25.52) was the strongest independent predictor for MACE followed by QTc $>468 \mathrm{~ms}$ (OR 2.6, $\mathrm{p}=0.018,95 \%$ CI 1.38-5.09) after adjusting for other variables. Troponin I, age, sex, diabetes, SBP <90 mmHg, Killip class higher than $1, \mathrm{LVEF}<35 \%$, and MV-CAD were not independent predictors of MACE.

\section{Discussion:-}

Troponin I levels correlated significantly with poor prognostic markers in ACS. Highest quartile of troponin I values was seen in patients who presented with higher TIMI scores, severe left ventricular systolic dysfunction ,higher killip class and hypotension. (similar to study by lindahl et al,) .In our study, Mean Troponin I value was also significantly higher in patients with multivessel disease on angiogram $(\mathrm{P}=0.005)$ with respect to single vessel disease group, and did not differ significantly according to culprit vessel.

In FRISC II study, Troponin T levels did not correlate with severity of underlying coronary artery disease on angiography ${ }^{13}$ But in recent studies in stable CAD patients high sensitivity troponin increases with number of vessels with significant stenosis, as well as number of significant stenosis. ${ }^{14}$

Mean QTc interval did not differ significantly between male and female \pm patients but varied significantly according to patient's age, with age ( $<70$ years, mean QTc was significantly lower, $\mathrm{p}=0,01$ ). with diabetes, $\mathrm{p}<0.001$ or dyslipidemia $(\mathrm{p}<0.001)$.

Mean QTc varied significantly according to TIMI score, killip class, systolic BP and left ventricular ejection fraction at presentation, with highest value in TIMI 5-7 group $(\mathrm{p}<0.001)$, killip class $>1,(\mathrm{p}<0.001), \mathrm{SBP}<90 \mathrm{~mm} \mathrm{Hg}$ and LVEF $<35 \%(\mathrm{p}<0.001)$ 
Multivessel disease have higher Mean QTc value compared to single vessel disease ( $\mathrm{p}=0.009$ ). The QTc values did not differ according to culprit vessel.Our finding were comparable from the study published by Jimenez -Candil et al in NSTEACS patients,

There was significant correlation between QTc Max and Troponin I level with a correlation coefficient of 0.637 between QTc-max and Troponin I, $(\mathrm{p}<0.001)$.

On multivariate analysis, Troponin I level was independently predicted by, Age group ( $\mathrm{p}=0.04)$, LVEF ( $\mathrm{p}<0.001)$, and TIMI score ( $\mathrm{p}<0.001)$, after adjusting for sex, diabetes, dyslipidemia , Killip class, SBP, ST deviation, and MV-CAD. Maximum QTc interval was independently predicted by LVEF $(\mathrm{p}<0.001)$ and TIMI score $(\mathrm{p}<0.001)$, after adjusting for all other variables.

Patients with MACE had significantly higher mean Troponin - I level higher mean QTc interval $(\mathrm{p}<0.001)$.

Mueller et al ${ }^{15}$,Lindahl et $\mathrm{al}^{13}$ showed that the risk of in hospital and long term mortality increased with absolute level of troponin-T.According to Gadaleta et al, ${ }^{9}$ Susan et al (reported QTc $\left.>0.458\right)^{16}$, Jimenez Candil et al ${ }^{17}$ the QTc interval was found to be an independent predictor of MACE risk in NSTEACS population.

\section{Limitation:}

This was a relatively small study sample, with even smaller number of patients in various subgroups, therefore a larger cohort of patients is required to further validate these results.

High sensitivity troponin assays are not widely available. Use of high sensitivity assays instead of conventional assay might affect the result of predictive model in multivariate analysi and long term follow up assessment of MACE is advisable.

\section{Conclusion:-}

Corrected QT interval has a strongly positive significant correlation with quantitative troponin I level in NSTEMI patients. Prolonged corrected QT interval is independently predictive of higher rate of major adverse cardiovascular events after NSTEMI within 30 days post discharge.

\section{Bibliography:-}

1. Amsterdam EA, Wenger NK, Brindis RG, Casey DE, Ganiats TG, Holmes DR, et al. 2014 AHA/ACC Guideline for the Management of Patients With Non-ST-Elevation Acute Coronary Syndromes. 1 Am CoIl Cardiol2014;64:e139-228.

2. Task Force for the Management of Acute Coronary Syndromes in Patients Presenting without Persistent STSegment Elevation of the European Society of Cardiology. 2015 ESC Guidelines for the management of acute coronary syndromes in patients presenting without persistent ST-segment elevation. Eur Heart J 2016;37;267315.

3. Antman EM, Tanasijevic Ml, Thompson B, Schactman M, McCabe CH, Cannon CP, et al. Cardiac-specific troponin I levels to predict the risk of mortality in patients with acute coronary syndromes. N Engl 1 Med 1996;335: 1342-9.

4. Ohman EM, Annstrong PW, Christens on RH, Granger CB, Katus HA, Hamm CW, et al. Cardiac troponin T levels for risk stratification in acute myocardial ischemia. GUSTO HA Investigators. N Engl J Med 1996;335:1333-41.

5. Morrow DA, Antman EM, Tanasijevic M, Rifai N, de Lemos JA, McCabe CH, et al. Cardiac troponin I for stratification of early outcomes and the efficacy of enoxaparin in unstable angina: a TIMI-IIB substudy. J Am Coll Cardiol 2000;36: 1812-7.

6. Olatidoye AG,., Wu AH, Feng YJ, Waters D. Prognostic role of troponin T versus troponin I in unstable angina pectoris for cardiac events with meta-analysis comparing published studies. Am J Cardiol 1998;81: 1405-1 O.

7. Gadaleta FL, Llois SC, Lapuente AR, Batchvarov VN, Kaski $l C$. Prognostic value of corrected QT-interval prolongation in patients with unstable angina pectoris. Am J Cardiol2003;92:203-5.

8. Jimenez-Candil, Gonzalez IC, Gonzalez JM, Albarran C, Pabon P, Monnigo JL, et al. Short- and long-term prognostic value of the corrected QT interval in the non-ST- elevation acute coronary syndrome. J ElectrocardlOl2007;40:180-7. 
9. Gadaleta FL, Llois SC, Sinisi VA, Quiles J, Avanzas P, Kaski JC. Corrected QT interval prolongation: a new predictor of cardiovascular risk in patients with non-ST- elevation acute coronary syndrome. Rev Esp Cardiol 2008;61:572-8.

10. Antman EM, Cohen M, Bernink $P l$, McCabe CH, Horacek T, Papuchis G, et al. The TIMI risk score for unstable angina/non-ST elevation MI: A method for prognostication and therapeutic decision making. JAMA 2000;284:835-42.

11. Rautaharju P, Surawicz M, Gettes J. AHA/ACCF/HRS Recommendations for the Standardization and Interpretation of the Electrocardiogram: Part IV: The ST Segment, T and U Waves, and the QT Interval. Circulation 2009;119:e241-50.

12. Luo S, Michler.K, Johnston P, Macfarlane PW. A comparison of commonly used QT correction formulae: the effect of heart rate on the QTc of normal ECGs. J ElectrocardioI2004;37Suppl:81-90.

13. Lindahl B, Diderholm E, Lagerqvist $B$, Venge $P$, Wallentin $L$, and FRISC II Investigators. Mechanisms Behind the Prognostic Value of Troponin T in Unstable Coronary Artery Disease: A FRISC II Substudy. J Am ColI Cardiol $2001 ; 38: 979-86$

14. Everett BM, Brooks MM, Vlachos H, Chaitman BR, Frye RL, Bhatt DL, for the BARI 2D Study Group. Troponin and Cardiac Events in Stable Ischemic Heart disease and Diabetes. N Engl J Med 2015;373:610-20.

15. Mueller C, Neumann FJ, Perruchoud AP, Zeller T, Buettner HJ. Prognostic value of quantitative troponin T measurements in unstable angina/non-ST -segment elevation acute myocardial infarction treated early and predominantly with percutaneous coronary intervention. Am J Med 2004 Dec 15; 117:897-902.

16. L10is SC, Gadaleta FL, Sinisi VA, Avanzas P, Kaski $l C$.. Prognostic Value of corrected QT Interval and its Correlation with Cardiac Troponin $\mathrm{T}$ in on-ST- Elevation Acute Coronary Syndrome. Rev Argent Cardio12012;80:432-7.

17. Jimenez-Candil J, Matas GJM, Gonzalez IC, Hemandes JH, Martin A, Pabon P, et al. In-hospital prognosis in non-ST-segment elevation acute coronary syndrome derived using a new risk score based on electrocardiographic parameters obtained at admission. Rev Esp Cardiol2010;63:851. 